\title{
Octadecylphosphonic Acid Self-Assembled Monolayers Obtained Using Rapid Dipping Treatments
}

\author{
Toshiya Bamba ${ }^{1}$, Tadashi Ohtake ${ }^{1}$, Yusuke Ohata, Heng-yong Nie ${ }^{2}$, Takahiko Ban ${ }^{1}$, and \\ Shin-ichi Yamamoto ${ }^{1 *}$ \\ 1 Department of Electronics and Informatics, Faculty of Science and Technology, Ryukoku University, \\ 1-5 Yokotani, Seta Oe-cho, Otsu, Shiga, 520-2194, Japan \\ 2 Surface Science Western, The University of Western Ontario, 999 Collip Circle, \\ London, N6G 0J3, Ontario, Canada. \\ * Corresponding author: Phone: +81-77-543-7404 Fax: +81-77-543-7428 E-mail: shin@rins.ryukoku.ac.jp
}

Self-assembled monolayers (SAMs) of amphiphilic organic molecules that form on a solid surface have generated an enormous amount of interest in interdisciplinary research areas as diverse as molecular engineering of surfaces, tribology, biology, nanotechnology, polymer composites, organic electronics, and analytical chemistry. We measured the contact angle to study the surface chemistry and structures of SAMs. Octadecylphosphonic acid (OPA) has the featureof being able to form a monomolecular film in an extremely short time (i.e., within several seconds). The analytical approaches developed in this study should be applicable to research and development related to controlling surface properties.

Keywords: self-assembled monolayer, metal oxide, contact angle (CA)

\section{INTRODUCTION}

A self-assembled monolayer (SAM) is an ultrathin film that spontaneously forms when a substrate is immersed in a solution of target molecules. The organic molecules chemically adsorb to the sample, and a 1-2 nm thick monomolecular film of organic molecules with a uniform orientation can form. SAMs have high orientation and stability, and various functionalities can be introduced to the solid surface by the terminal functional group. [1]

Self-assembled monomolecular films formed by the adsorption and binding of organic molecules on a solid surface have been studied for their simplicity of production and wide range of applications. Representative types are silane and thiol. A conventional silane- or thiol-type monomolecular film can take as long as 1-24 h to form. [2-3] However, octadecylphosphonic acid (OPA) has the feature of being able to form a monomolecular film in an extremely short time (i.e., within several seconds) [4-8]. Phosphonic acid-based SAMs are stable with high orientation in natural oxide films and metal oxides of metals and alloys. Hoque et al. [9] reported that organic silanes terminated with a fluoroalkyl group $\left(\mathrm{CF}_{3}\left[\mathrm{CF}_{2}\right]_{7} \mathrm{CH}_{2}\left[\mathrm{CH}_{3}\right]_{2} \mathrm{SiCl}\right)$ and phosphonic acid $\left(\mathrm{CF}_{3}[\mathrm{CF}\right.$ $\left.\left.{ }_{2}\right]_{7} \mathrm{CH}_{2} \mathrm{CH}_{2} \mathrm{PO}\left[\mathrm{OH}_{2}\right]\right)$ and three kinds of alkyl group-terminated phosphonic acids $\left(\mathrm{CH}_{3}\left[\mathrm{CH}_{2}\right]_{\mathrm{n}} \mathrm{PO}[\mathrm{OH}]_{2 \mathrm{n}}\right.$ $=7,9,17)$ formed SAMs on the surface of a Si substrate on which $\mathrm{Al}$ was deposited. They examined the chemical resistance (nitric acid [pH 1.8], $60-95{ }^{\circ} \mathrm{C}$ ). Their results showed that the SROs at the end of the fluoroalkyl group exhibited high hydrophobicity with a water droplet contact angle of $130^{\circ}$, whereas the OPA-SAMs had the highest chemical resistance stability. In this study, a monomolecular film was formed on $\mathrm{Al}$ to form the natural oxide film $\mathrm{Al}_{2} \mathrm{O}_{3}$. Furthermore, changes in the surface structure of the metal oxide thin film were investigated by forming a metal oxide thin film on the surface of the monomolecular film.

\section{EXPERIMENTS}

2.1 Experimental details

A thin Al film was formed on a Si substrate (P type $100)$ with a resistance heating deposition apparatus. Ultraviolet rinsing was carried out for $10 \mathrm{~min}$ with a low-pressure mercury lamp. Then, OPA-SAMs were formed on the Al thin film with the dip coating method. For the dip coat solution, OPA $\left(\mathrm{C}_{18} \mathrm{H}_{39} \mathrm{O}_{3} \mathrm{P}\right)$ manufactured by Tokyo Chemical Industry Co., Ltd. was prepared as a solute with anisole $\left(\mathrm{C}_{7} \mathrm{H}_{8} \mathrm{O}\right)$ manufactured by Sigma-Aldrich as a solvent and pulled up. The pulling down speed was $1 \mathrm{~mm} / \mathrm{s}$. The film quality of the OPA-SAMs was evaluated according to the wettability represented by the water drop contact angle and X-ray photoelectron spectroscopy (XPS).

A monomolecular film was then applied as a base layer to metal oxide thin films. Bismuth vanadate oxide $\left(\mathrm{BiVO}_{4}\right)$ [10-14] and oxidized titanium $\left(\mathrm{TiO}_{2}\right)$ [15-17], which are photocatalytic materials, were used for the metal oxide thin films. A sputtering method was used to deposit the metal oxide thin films. The surface characteristics were evaluated with a scanning electron microscope (SEM) and scanning probe microscope (SPM).

Fig. 1 shows the binding model of OPA-SAMs on an $\mathrm{Al}$ thin film. The film quality of the OPA-SAMs was evaluated. The OPA-SAMs were used as underlayers for the formation of metal oxide thin films, and the state of the metal oxide thin film surface was evaluated. 


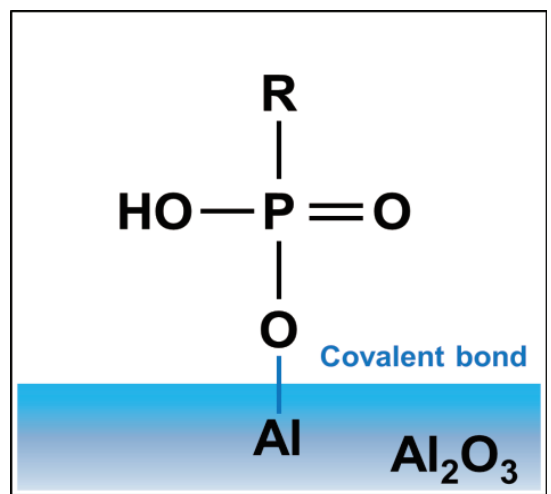

Fig. 1 Schematic illustration of OPA molecules in OPA/Al. R represents OPA' s alkyl chain of $\mathrm{CH}_{3}\left(\mathrm{CH}_{2}\right)_{17}$

2.2 Monomolecular Film Used as an Underlayer to Form Metal Oxide Thin Films

$\mathrm{BiVO}_{4}$ and $\mathrm{TiO}_{2}$ were used as photocatalyst materials for the metal oxide thin films. A sputtering method was used to form the metal oxide thin films. Table 1 presents the deposition conditions for the two metal oxide thin films.

Table 1 Film forming conditions.

\begin{tabular}{|c|c|c|c|c|c|}
\hline Target & Gas & Flow rate & Pressure & Time & $\begin{array}{c}\text { Electric } \\
\text { power }\end{array}$ \\
\hline BivO $_{4}$ & Ar & 2.5 & 1.0 & 90 & 50 \\
\hline $\mathrm{TiO}_{2}$ & $\mathrm{~N}_{2}$ & 1.0 & 3.0 & 180 & 50 \\
\hline
\end{tabular}

\section{RESULTS AND DISCUSSION}

3.1 Water Drop Contact Angle Measurement

Table 2 presents water droplet images taken after OPA-SAMs were formed by the dip coating method. The surface of the $\mathrm{Al}$ thin film not cleaned with ultraviolet rays was covered with an oxide film having a thickness of several nanometers as well as organic pollutants. When surface treatment was applied to the substrate with a low-pressure mercury lamp, the water droplet contact angle decreased to less than $5^{\circ}$, and the organic contaminants on the substrate surface were removed. After the thin film was dipped in the dip coat solution, the water drop contact angle showed a remarkable increase. This may be because the hydroxyl groups on the surface of the $\mathrm{Al}$ thin film and those of OPA reacted and bonded to each other to form SAMs, which demonstrated hydrophobicity. Fig. 2 shows the water droplet contact angle against the time of immersion in the dip coat solution. As the dipping time increased, the density of SAMs on the Al thin film surface increased, which increased the water droplet contact angle. When the immersion time was $60 \mathrm{~s}$ or less, the water droplet contact angle became almost constant. This indicates that sufficient SAMs were formed.

When anisole was used as the solvent, it was found that it took 60 seconds to form a monomolecular film at a high density. Next, the immersion time was kept constant for 60 seconds, and the kind of solvent was changed. Three types of solvents, water, ethanol and anisole, were prepared. The results are shown in Fig. 3. When water was used as the solvent, the contact angle was $80^{\circ}$. By using ethanol and anisole as a solvent, the water droplet contact angle became $90^{\circ}$ or more, and high hydrophobicity was exhibited. This is thought to be due to the dielectric constant of the solvent. The dielectric constant at room temperature $25^{\circ} \mathrm{C}$. is 24.6 for ethanol, 4.3 for anisole and 78.3 for water. Since the dielectric constant is low, the solute OPA is sufficiently dissolved in the solvent. Therefore, OPA-SAMs with high density were formed, and it seems that they showed high hydrophobicity.

Table 2 Water contact angles measured on $\mathrm{OPA}-\mathrm{SAMs} / \mathrm{Al} / \mathrm{Si}$ samples as a function of

\begin{tabular}{|c|c|c|c|c|c|c|}
\hline $\begin{array}{l}\text { Immersion time } \\
\quad \text { (sec.) }\end{array}$ & 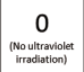 & 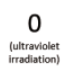 & 5 & 15 & 30 & 45 \\
\hline $\begin{array}{l}\text { Water contact angle } \\
\text { (deg.) }\end{array}$ & $87^{\circ}$ & $<5^{\circ}$ & $83^{\circ}$ & $84^{\circ}$ & $94^{\circ}$ & $94^{\circ}$ \\
\hline $\begin{array}{l}\text { Immersion time } \\
(\text { sec. })\end{array}$ & 60 & 120 & 240 & 360 & 480 & 600 \\
\hline $\begin{array}{l}\text { Water contact angle } \\
\text { (deg.) }\end{array}$ & & & & & & \\
\hline
\end{tabular}

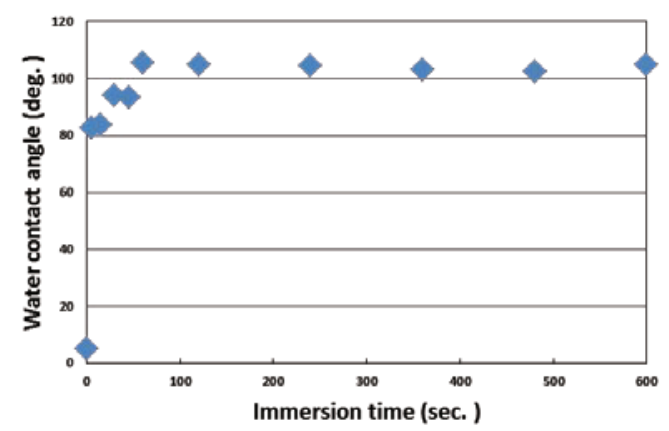

Fig. 2 Water contact angles measured on OPA-SAMs/Al/Si samples as a function of the immersion time.

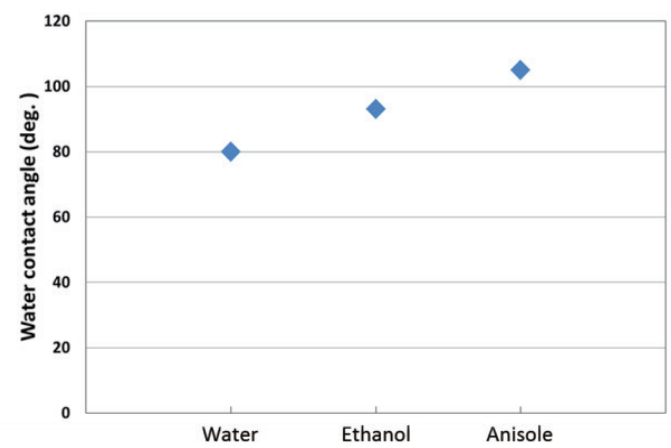

Fig. 3 Water drop contact angle when changing three solvent types 


\subsection{XPS Measurements}

Samples were measured with XPS before SAM deposition $(\mathrm{Al} / \mathrm{Si})$ and after $\mathrm{SAM}$ deposition (OPA-SAM/Al/Si). As a sample with a monomolecular film, a sample prepared with an immersion time of 60 seconds was used. Fig. 4(a) shows the XPS measurements in the spectral range $(280-295 \mathrm{eV})$ of C1s of SAMs before film formation $(\mathrm{Al} / \mathrm{Si})$, and Fig. 4(b) shows the results after SAM film formation (OPA-SAMs/Al/Si). The energy correction (charge correction) of the measured XPS spectrum was performed by using $\mathrm{Cls}$ of the surface-contaminating hydrocarbons as a reference. (The theoretical peak energy value of the surface-contaminating hydrocarbon is $284.6 \mathrm{eV}$.) [18-22]) The measured values for the surface energy of the surface-contaminating hydrocarbon before and after film formation were both $286.4 \mathrm{eV}$, as shown in Figs. 4(a) and (b). The charge correction was evaluated as $1.8 \mathrm{eV}$. These results confirmed that the spectrum of $\mathrm{CO}_{3}$ lowered when SAMs were deposited. This is probably because the surface contaminants were decomposed and removed by ultraviolet irradiation before the film formation of the SAMs.

Fig. 5(a) shows the spectral range (125-140 eV) of $\mathrm{P} 2 \mathrm{p}$ before SAMs film formation $(\mathrm{Al} / \mathrm{Si})$, and Fig. 5(b) shows the range after SAMs film formation (OPA-SAMs/Al/Si). These were obtained from the XPS measurement. The results of the charge correction confirmed the peak of $\left(\mathrm{PO}_{4}\right)^{3-}(133.2 \mathrm{eV})$ in Fig. 5(a) and peaks of $\left(\mathrm{PO}_{4}\right)^{3-}$ and $\left(\mathrm{PO}_{3}\right)^{-}(134.6 \mathrm{eV})$ in Fig. 5(b). The peak of $\left(\mathrm{PO}_{3}\right)^{-}$is not in Fig. 5(a) but appears in Fig. 5(b). This suggests that functional groups based on phosphonic acid are present on the substrate surface when SAMs are deposited.

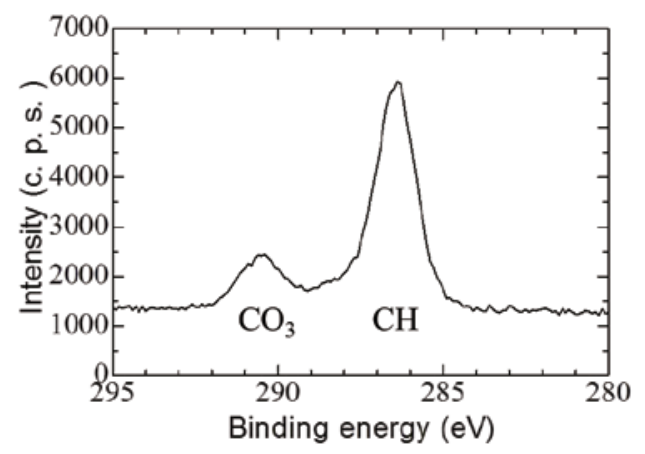

(a) $\mathrm{Al} / \mathrm{Si}$

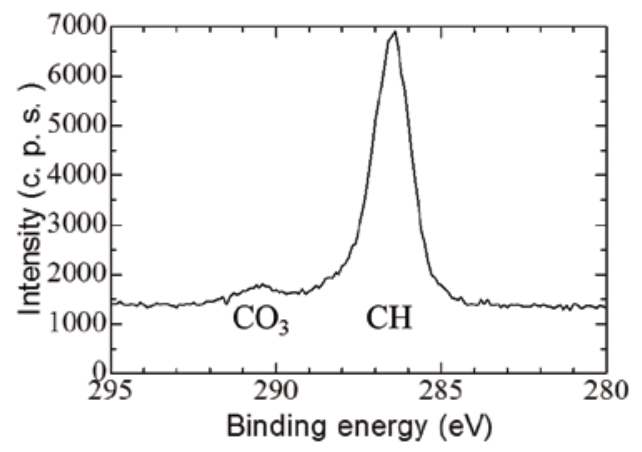

(b) OPA SAMs $/ \mathrm{Al} / \mathrm{Si}$

Fig. 4 XPS spectra of samples in the $C(2 p)$ region: (a) $\mathrm{Al} / \mathrm{Si}$ and (b) OPA-SAMs/Al/Si.

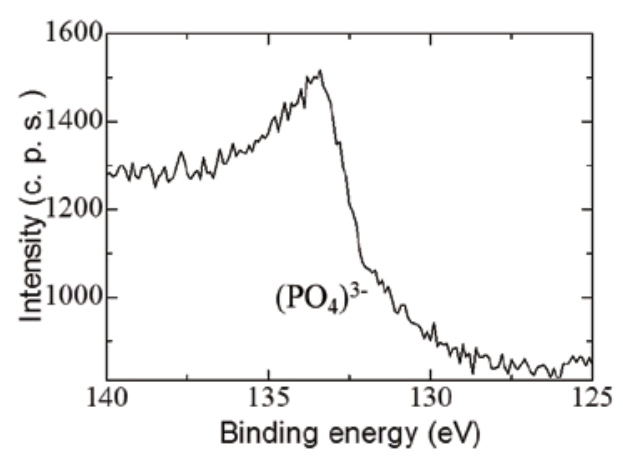

(a) $\mathrm{Al} / \mathrm{Si}$

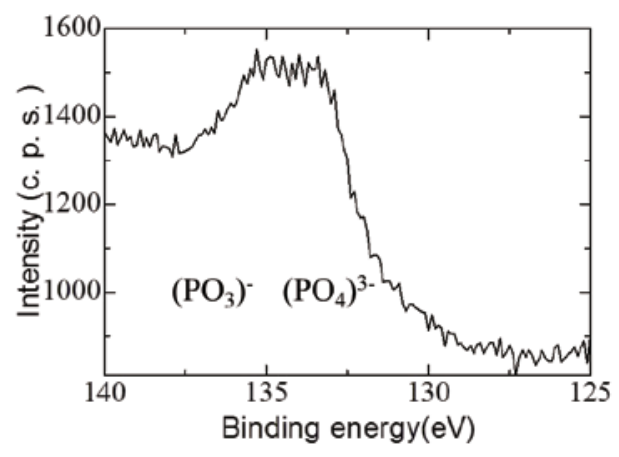

(b) OPA-SAMs/Al/Si

Fig. 5 XPS spectra of samples in the P (2p) region:

(a) $\mathrm{Al} / \mathrm{Si}$ and (b) OPA-SAMs/Al/Si.

\begin{abstract}
3.4 SEM Measurements
$\mathrm{A} \mathrm{BiVO}_{4}$ thin film, which is a metal oxide thin film and photocatalytic material, was formed on an $\mathrm{Al}$ thin film or SAMs by RF sputtering. The surface of the prepared sample was observed with SEM. Fig. 6(a) shows the SEM image of a sample $\left(\mathrm{BiVO}_{4} / \mathrm{Al} / \mathrm{Si}\right)$ without $\mathrm{SAMs}$ that formed on the underlying film, and Fig. 6(b) shows the SEM image of a sample $\left(\mathrm{BiVO}_{4} / \mathrm{Al} / \mathrm{Si}\right)$ with $\mathrm{SAMs}$ as the underlying film. Measurements were performed at an acceleration voltage of $15.0 \mathrm{kV}$ and magnification of 100,000 times. These SEM images confirm that the size and number of particles on both sample surfaces changed. By forming a monomolecular film, the particle diameter of $\mathrm{BiVO}_{4}$ became smaller and the number of particles increased. It is considered that the film density increases as the deposition time in the sputtering apparatus becomes long. At the same time, it can be expected that the surface energy tends to decrease. This may be because the surface free energy changed when SAMs were formed in the underlying film, which affected the deposition.
\end{abstract}




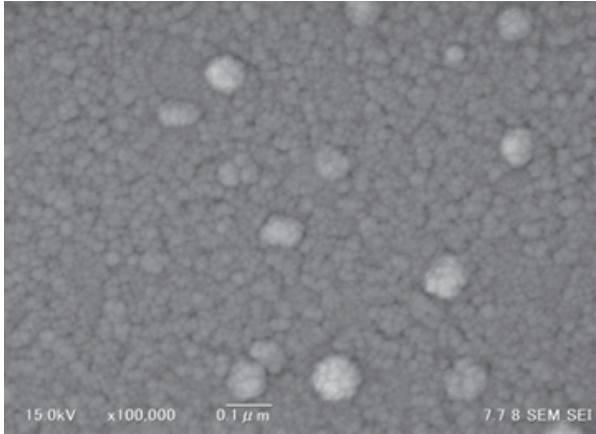

(a) $\mathrm{BiVO}_{4} / \mathrm{Al} / \mathrm{Si}$

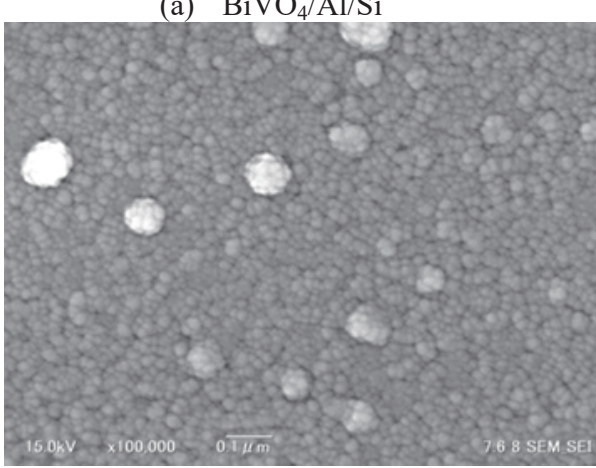

(b) $\mathrm{BiVO}_{4} / \mathrm{OPA}-\mathrm{SAMs} / \mathrm{Al} / \mathrm{Si}$

Fig. 6 SEM surface morphology of the sample layers: (a) $\mathrm{BiVO}_{4} / \mathrm{Al} / \mathrm{Si}$ and (b) $\mathrm{BiVO}_{4} / \mathrm{OPA}-\mathrm{SAMs} / \mathrm{Al} / \mathrm{Si}$.

\subsection{SPM Observations}

Fig. 7(a) shows an SPM image of the sample without OPA-SAMs $\left(\mathrm{BiVO}_{4} / \mathrm{Al} / \mathrm{Si}\right.$ ) (scanning range: $\left.1 \mu \mathrm{m}^{2}\right)$, and Fig. 7(b) shows an SPM image of the sample with OPA-SAMs $\left(\mathrm{BiVO}_{4} / \mathrm{OPA}-\mathrm{SAM} / \mathrm{Al} / \mathrm{Si}\right)$. A sample with a dipping time of $60 \mathrm{~s}$ was used as the monomolecular film. Three samples were prepared under each film formation condition. Each sample was measured with SPM three times. The images are representative of each condition. Fig. 7(a) shows that the size of the smallest particle unit was non-uniform, and the mountain consisting of the smallest particle unit had high unevenness. On the other hand, Fig. 7(b) shows that the size of the smallest particle unit was relatively uniform, and the mountain had relatively low unevenness. Table 3 presents the calculated particle number and size in the range measured with SPM. Adding OPA-SAMs increased the particle number by about $55 \%$ and decreased the particle size by about $75 \%$.

A similar experiment was conducted by changing the metal oxide thin film from $\mathrm{BiVO}_{4}$ to $\mathrm{TiO}_{2}$. Fig. 8 shows the SPM images of (a) $\mathrm{TiO}_{2} / \mathrm{Al} / \mathrm{Si}$ and (b) $\mathrm{TiO}_{2} / \mathrm{OPA}-\mathrm{SAMs} / \mathrm{Al} / \mathrm{Si}$. Similar to the $\mathrm{BiVO}_{4}$ thin film, Fig. 8(a) shows that the size of the smallest particle unit was non-uniform, and the peaks and valleys of the mountains consisting of the smallest particle unit were large. On the other hand, Fig. 8(b) shows that the size of the smallest particle unit was relatively uniform, and the unevenness of the mountain was relatively small. Table 4 presents the calculated particle number and size in the range measured with SPM. Adding OPA-SAMs increased the particle number by about $47 \%$ and reduced the particle size by about $15 \%$.
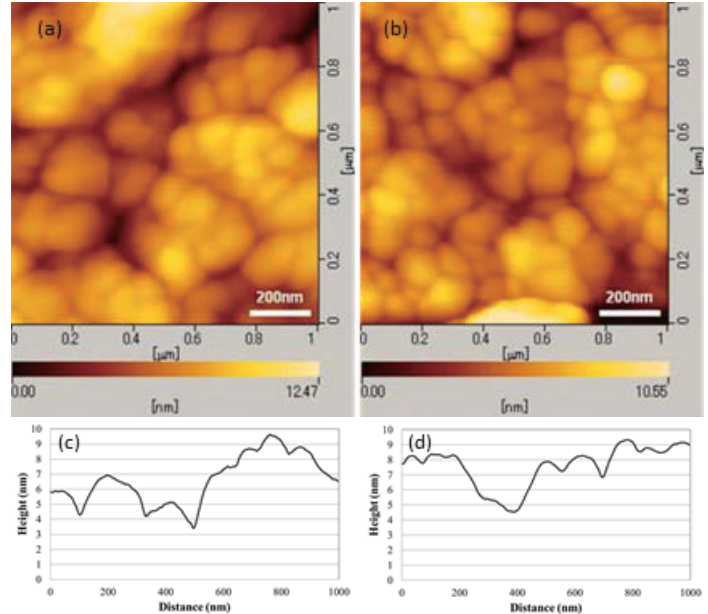

Fig. 7 SPM surface morphology of samples:

(a) $\mathrm{BiVO}_{4} / \mathrm{Al} / \mathrm{Si}$, (b) $\mathrm{BiVO}_{4} \mathrm{OPA}-\mathrm{SAMs} / \mathrm{Al} / \mathrm{Si}$,

(c) cross-sectional profile of $\mathrm{BiVO}_{4} / \mathrm{Al} / \mathrm{Si}$,

(d) cross-sectional profile of $\mathrm{BiVO}_{4} / \mathrm{OPA}-\mathrm{SAMs} / \mathrm{Al} / \mathrm{Si}$.

Table 3 Particle number, size, and $\mathrm{Ra}$ of $\mathrm{BiVO}_{4} / \mathrm{Al} / \mathrm{Si}$ and $\mathrm{BiVO}_{4} / \mathrm{OPA}-\mathrm{SAMs} / \mathrm{Al} / \mathrm{Si}$.

\begin{tabular}{|c|c|c|c|}
\hline Sample & Ra [nm] & Number & Particle size [nm] \\
\hline BiVO $_{4} / \mathrm{Al} / \mathrm{Si}$ & 1.6 & 67 & $98 \pm 24$ \\
\hline BiVO $_{4} / \mathrm{OPASAMs} / \mathrm{Al} / \mathrm{Si}$ & 1.2 & 104 & $24 \pm 8$ \\
\hline
\end{tabular}

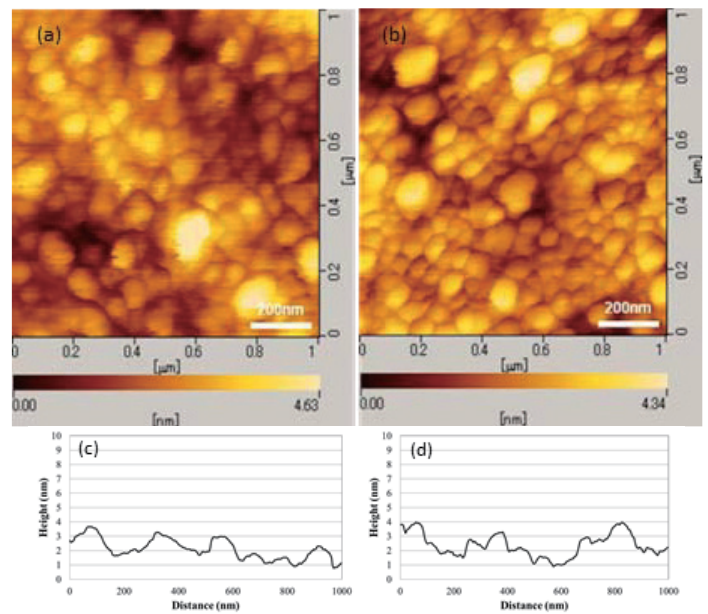

Fig. 8 SPM surface morphology of samples:

(a) $\mathrm{TiO}_{2} / \mathrm{Al} / \mathrm{Si}$ and (b) $\mathrm{TiO}_{2} / \mathrm{OPA}-\mathrm{SAMs} / \mathrm{Al} / \mathrm{Si}$.

(c) Cross-sectional profile of $\mathrm{TiO}_{2} / \mathrm{Al} / \mathrm{Si}$ and

(d) Cross-sectional profile of $\mathrm{TiO}_{2} / \mathrm{OPA}-\mathrm{SAMs} / \mathrm{Al} / \mathrm{Si}$ 
Table 4 Particle numbers, size, and $\mathrm{Ra}$ of $\mathrm{TiO}_{2} / \mathrm{Al} / \mathrm{Si}$ and

\begin{tabular}{|c|c|c|c|}
\hline \multicolumn{4}{|c|}{$\mathrm{TiO}_{2} / \mathrm{OPA}-\mathrm{SAM} / \mathrm{Al} / \mathrm{Si}}$. \\
\hline Sample & Ra [nm] & Number & Particle size [nm] \\
\hline $\mathrm{TiO}_{2} / \mathrm{AI} / \mathrm{Si}$ & 0.6 & 126 & $20 \pm 6$ \\
\hline $\mathrm{TiO}_{2} /$ OPA SAMs/Al/Si & 0.5 & 186 & $17 \pm 6$ \\
\hline
\end{tabular}

\section{CONCLUSION}

This study focus on the state of organic molecule SAMs on an Al thin film. Chemically decorating the $\mathrm{Al}$ thin film surface with a phosphonic acid SAM realized a surface exhibiting excellent hydrophobicity. The immersion time with the dip coating method was found to be important. Meanwhile, OPA-SAMs were used as a base layer of metal oxide thin films. Sputtering formation of the metal oxide films demonstrated that forming OPA-SAMs as an underlayer reduced the particle size of the oxide surface. One of the reasons may be the favorable surface energy of OPA-SAMs. In the future, we will study the structure of various metal oxide thin films in detail.

\section{REFERENCES}

[1] A. Ulman, Chem. Rev. , 96, 1533-1554, (1996).

[2] T. Ohtake and K. Ogawa, J. Dispersion Sci. Technol. 32, 439, (2011)

[3] K. Ogawa, T. Ohtake and T. Nomura, Jpn. J. Appl. Phys. , 41, 6471, (2002)

[4] H.-Y. Nie, D. Chen, H.K.Y. Wu, S. Naderi-Gohar, Y. $\mathrm{Wu}$, and Y. Huang, Journal of Materials Chemistry C, 2, 9941-9948, (2014).

[5] H.-Y. Nie, Analytical Methods, 5, 4911-4920, (2013).

[6] H-Y. Nie, Analytical Chemistry, 82, 3371-3376, (2010).

[7] H. -Y. Nie, N.S. McIntyre, W. M. Lau, Journal of Physics: Conference Series , 61, 864-873, (2007).

[8] H. -Y. Nie, Mary J. Walzak, and N. Stewart McIntyre, J. Phys. Chem. B, 110, 21101-21108, (2006).

[9] E. Hoque, J.A. DeRose, P. Hoffmann, B. Bhushan, and H.J. Mathieu, Journal of Physical Chemistry C, 111, 3956-3962, (2007).

[10] K.K. Chattopadhyay, S. Sarkar and N. S. Das, Solid State Sciences, 33, 58-66, (2014).

[11] A. Galembeck, O. L. Alves, Thin Solid Films, 365, 90-96, (2000).

[12] Songmei Sun, Wenzhohg Wang, Lin Zhou, and Haolan Xu, Ind. Eng. Chem. Res. , 48, 1735-1739, (2009).

[13] S. Sarkar, N. S. Das, K. K. Chattopadhyay, Solid State Sciences, 33, 58-9-66, (2014).

[14] Le Chen, Esther Alarcon-Llado, Mark Hettick, Ian D. Sharp, Yongjing Lin, Ali Javey, and Joel W. Ager, J. Phys. Chem. C, 117, 21635-21642, (2013).

[15] D. Mergel, P. Lobl, and M. Huppertz, Thin Solid Films, 251, 72-79, (1994).

[16] Cheol Ho Heo, Soon-Bo Lee, Jin-Hyo Boo, Thin Solid Films, 475, 183-188, (2005).

[17] Teruhisa Ohno, Takahiro Mistui, and Michio Mastumura, The Chemical Society of Japan, Vol. 32, No. 4, 364-365, (2003).

[18] N.S. McIntyre, H. -Y. Nie, A. P. Grosvenor, R. D.
Davidson and D. Briggs, surface and interface analysis, 37, 749-754, (2005).

[19] P. Swift, Surface and Interface Analysis, 4, 47-51, (1982).

[20] S. Takabayashi, K. Okamoto, H. Motoyama, T. Nakatani, H. Sakaue, and T. Takahagi, Surface and Interface Analysis, 42, 77-87, (2010).

[21] S. Kohiki and K. Oki, Journal of Electron Spectroscopy and Related Phenomena, 33, 375-380, (1984).

[22] Z.F. Ren, Z.P. Huang, J.W. Xu, J.H. Wang, P. Bush, M.P. Siegal, and P.N. Provencio, Science, 282, 1105-1107 (1998).

(Received June 9, 2018; Accepted August 19, 2018; Published Online October 1, 2018) 